\title{
Análise Petrofísica da Tufa Carbonática do Afloramento Felipe Guerra, Bacia Potiguar.
}

Sousa, W.B. ${ }^{1}$; Soares, J.A. ${ }^{1}$; Freire, L. A. ${ }^{1}$

${ }^{1}$ Universidade Federal de Campina Grande.

Copyright 2014, SBGf - Sociedade Brasileira de Geofísica

Este texto foi preparado para a apresentação no VI Simpósio Brasileiro de Geofísica, Porto Alegre, 14 a 16 de outubro de 2014. Seu conteúdo foi revisado pelo Comitê Técnico do VI SimBGf, mas não necessariamente representa a opinião da SBGf ou de seus associados. É proibida a reprodução total ou parcial deste material para propósitos comerciais sem prévia autorização da SBGf.

\section{Resumo}

Neste trabalho são apresentadas as propriedades físicas da tufa carbonática de um afloramento da Formação Jandaíra, na Bacia Potiguar. As propriedades analisadas são: porosidade, permeabilidade, as densidades de grãos e total, e as velocidades de propagação das ondas elásticas. Os módulos elásticos são derivados das velocidades e da densidade total. Os resultados obtidos mostram uma variação da densidade de grãos que vai de 2,61 até $2,73 \mathrm{~g} / \mathrm{cm}^{3}$. Esta variação pode ser devido à presença de matéria orgânica, argila e/ou material siliciclástico. Foi estabelecida uma relação linear confiável entre a densidade total e a porosidade. A relação entre permeabilidade e porosidade indica uma variação granulométrica considerável, ou, alternativamente, a presença de porosidade dos tipos intergranular, vugular e microporosidade. As amostras analisadas apresentam, em sua maioria, níveis médios a baixos de anisotropia elástica.

\section{Introdução}

Tufa é uma variedade de calcário formada em água com temperatura ambiente. As tufas se diferenciam dos travertinos por seus ambientes deposicionais e pela temperatura da água. Os depósitos de tufas apresentam restos de bactérias, plantas ou animais, com graus de cimentação e idades variadas, enquanto que os travertinos apresentam atividades microbianas, principalmente os micro-organismos resistentes ao calor, como as diatomáceas. O desenvolvimento das tufas associa-se a fenômenos cársticos, controlados por fatores morfológicos, hidrogeológicos, hidroquímicos, biológicos e climáticos. A precipitação bioquímica da calcita em tufas é controlada pelo conteúdo de $\mathrm{CO}_{2}$, pela pressão, temperatura e bioquimicamente pela fotossíntese (FORD \& PEDLEY, 1996; SUGUIO, 2003).

\section{Aspectos geológicos}

A Bacia Potiguar está inserida no nordeste brasileiro, englobando grande parte do Estado do Rio Grande do Norte e uma pequena parte do nordeste do Estado do Ceará. Essa Bacia é do tipo rifte, com formação no neojurássico, a partir da separação das placas africana e sul-americana. Juntamente com uma série de bacias neocominianas, a Bacia Potiguar compõe o sistema rifite do nordeste brasileiro (CASSAB, 2003; CÓRDOBA, 2001; PÉREZ, 2003). Esta Bacia apresenta rochas organizadas em três grupos: Areia Branca, Apodi e
Agulha. No grupo Apodi se encontra a Formação Jandaíra, da qual foram extraídas as amostras de tufa carbonática analisadas neste trabalho. O afloramento visitado se encontra ao lado da igreja católica localizada no centro da cidade de Felipe Guerra, RN.

\section{Preparo de amostras}

As amostras analisadas neste trabalho foram preparadas a partir de um bloco retirado da área de estudo concentrada no município de Felipe Guerra - RN, situada na microrregião da Chapada do Apodi. Na sala de preparação de amostras o bloco foi serrado e transformado em blocos menores dos quais foram extraídos os plugues, obtidos por meio de plugadeira de bancada (Figura 1b). Os plugues têm uma polegada e meia de diâmetro e aproximadamente $5 \mathrm{~cm}$ de comprimento. Em seguida fez-se o desbaste dos plugues, utilizando para isso uma retificadora de plugues (Figura 1c). A retificação é importante para garantir aos plugues extremidades com faces planas e paralelas, característica necessária para os ensaios petrofísicos.

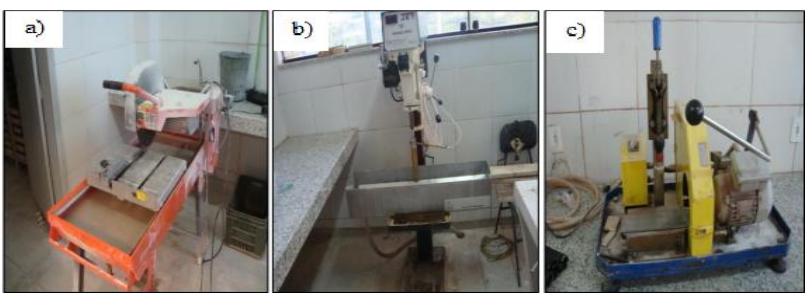

Figura 1 - a) Serra, b) Plugadeira e c) Retificadora.

Terminado o preparo das amostras, as mesmas são levadas para a sala de análises do Laboratório de Petrofísica da UFCG, onde são colocadas para secar numa estufa (Figura 2a) a uma temperatura de $80^{\circ} \mathrm{C}$ por 24 horas. Após secas, as amostras são pesadas em uma balança eletrônica de precisão (Figura $2 b$ ) e tem seu diâmetro e comprimento medidos. Para medir as dimensões das amostras, utiliza-se um paquímetro digital (Figura 2c).

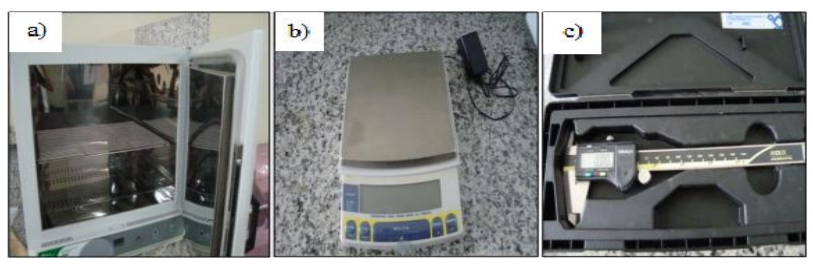

Figura 2 - a) Estufa, b) Balança eletrônica de precisão e c) Paquímetro digital.

A Figura 3 apresenta uma fotografia de um conjunto de amostras de tufa carbonática prontas para a realização dos ensaios petrofísicos. 




Figura 3 - Exemplo de amostras de tufa carbonática preparadas para os ensaios petrofísicos.

\section{Ensaios de porosidade e de densidade de grãos}

As análises laboratoriais iniciam-se com a medição da porosidade e da densidade de grãos em permoporosímetro a gás. O plugue é colocado dentro do copo matriz onde seu volume de grãos é medido. A diferença entre o volume total do plugue e o volume de grãos corresponde ao volume de vazios da amostra. A razão entre o volume de vazios e o volume total é a porosidade.

O equipamento UltraPoroPerm $500^{\circledR}$ (Figura 4), de fabricação Corelab, é a combinação de um instrumento de medição de volume de grãos e de permeabilidade acoplado a uma câmara simples de compressão hidrostática (coreholder).

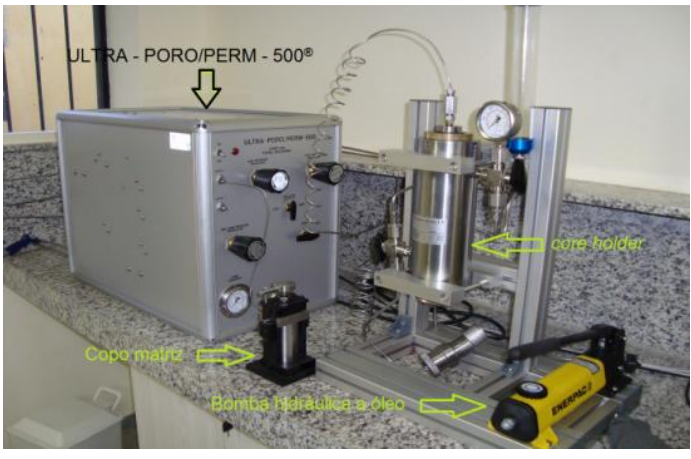

Figura 4 - Permoporosímetro a gás.

Para medição da porosidade o equipamento se baseia na lei de Boyle-Mariotte, que relaciona as variações de volume e pressão de um gás ideal em temperatura constante.

O porosímetro contém uma câmara de gás de volume constante $V_{1}$, na qual nitrogênio é injetado e armazenado a uma pressão $P_{1}$. Esta câmara está ligada ao copo matriz, de volume $V_{C}$. Uma amostra de rocha de volume $V_{A}$ é inserida no copo matriz juntamente com discos metálicos de volume $V_{D}$. Em seguida o copo matriz é fechado e uma válvula é aberta permitindo a expansão do gás para o copo matriz. $O$ gás passa a ocupar os vazios no copo matriz $(\Delta V)$, além do volume $V_{1}$, o que resulta em uma queda de pressão do gás para o nível $P_{2}$ : $P_{1} V_{1}=P_{2}\left(V_{1}+\Delta V\right)$. Mas o volume de vazios é $\Delta V=V_{C}$ $-V_{D}-V_{G}$ onde a única incógnita é o volume de grãos da amostra $\left(V_{G}\right)$.

\section{Ensaios de permeabilidade}

Para os ensaios de permeabilidade utiliza-se, também, o UltraPoroPerm $500^{\oplus}$ porém, em substituição ao copo matriz, utilizamos o coreholder. No interior do coreholder há um cilindro vazado de borracha onde a amostra é inserida e limitada, em sua parte superior e inferior, por dois êmbolos móveis de aço adaptáveis ao tamanho da amostra. Para impor pressão de confinamento à amostra de rocha, há uma bomba hidráulica conectada ao coreholder. Neste trabalho a pressão confinante utilizada foi $2.000 \mathrm{psi}$.

O permeâmetro a gás (Figura 4) trabalha de acordo com a lei de Darcy, onde para calcular a permeabilidade utiliza a seguinte expressão:

$$
\mathrm{K}=\frac{2000 \mathrm{P}_{1} \mu \mathrm{Q}_{1} \mathrm{~L}}{\mathrm{~A}\left(\mathrm{P}_{1}^{2}-\mathrm{P}_{2}^{2}\right)}
$$

onde

$\mathrm{K}=$ permeabilidade absoluta $(\mathrm{mD})$;

$\mu=$ viscosidade do fluido (cP);

$\mathrm{Q}_{1}=$ taxa de fluxo do gás $\left(\mathrm{cm}^{3} / \mathrm{s}\right)$;

$\mathrm{L}=$ comprimento da amostra $(\mathrm{cm})$;

$P_{1}=$ pressão de entrada do gás (atm);

$\mathrm{P}_{2}=$ pressão de saída do gás (atm);

$\mathrm{A}=$ área da seção transversal da amostra $\left(\mathrm{cm}^{2}\right)$

\section{Ensaios elastodinâmicos}

Os ensaios elastodinâmicos têm como objetivo medir a velocidade de propagação das ondas $\mathrm{P}, \mathrm{S}_{1}$ e $\mathrm{S}_{2}$. Esses ensaios são realizados utilizando o equipamento Autolab $500^{\circledast}$, produzido pela New England Resarch (Figura 5). Este ensaio realiza a medição do tempo de trânsito da transmissão direta de ondas elásticas que percorrem a amostra ao longo do seu comprimento axial.



Figura 5 - Câmara de medição de velocidades de ondas elásticas sob condições controladas de pressão e temperatura.

Os ensaios elastodinâmicos foram realizados em 38 amostras secas, com pressão de poros e temperatura nas condições normais do ambiente. A pressão confinante inicial foi estabelecida em $20 \mathrm{MPa}$. O tempo de trânsito na amostra deve ficar estável a esta pressão por no mínimo 5 minutos, quando se captura a primeira onda. O tempo de estabilização depende do tipo de amostra. Após a primeira onda ser capturada, as demais 
ondas com pressão de 15, 10 e $5 \mathrm{MPa}$, são capturadas quando permanecem estáveis por no mínimo 2 minutos.

Depois de capturadas todas as ondas, faz-se a picagem das mesmas no software de aquisição e processamento dos dados. Esta etapa consiste em marcar os tempos de chegada das ondas $\mathrm{P}, \mathrm{S}_{1}$ e $\mathrm{S}_{2}$. Com isso será obtido um relatório contendo os módulos de Young, os coeficientes de Poisson e as velocidades elásticas para todas as ondas capturadas.

A velocidade de cada onda elástica é determinada pela razão entre o comprimento da amostra e o tempo de propagação daquela onda.

Com base nos dados das velocidades elásticas e da densidade total, calculam-se os módulos elásticos: Módulo de elasticidade (E), Módulo de incompressibilidade (K), Módulo de cisalhamento $(\mathrm{G})$, e razão de Poisson $(v)$. As expressões usadas para o cálculo dos módulos elásticos são derivadas da teoria geral da elasticidade e encontram-se descritas na literatura especializada.

\section{Resultados e Discussões}

A Figura 6 apresenta as velocidades das ondas $P$, em função da pressão confinante, para as 38 amostras ensaiadas. Nesta figura se observa que ocorre um aumento da velocidade com o aumento da pressão confinante. Nota-se também que, embora a composição esperada das amostras seja aproximadamente a mesma - uma vez que todas provêm de um mesmo afloramento as velocidades das amostras, para uma dada pressão confinante, variam dentro de um intervalo de cerca de 1400 m/s, ou seja, cerca de 23\% em relação à velocidade média.

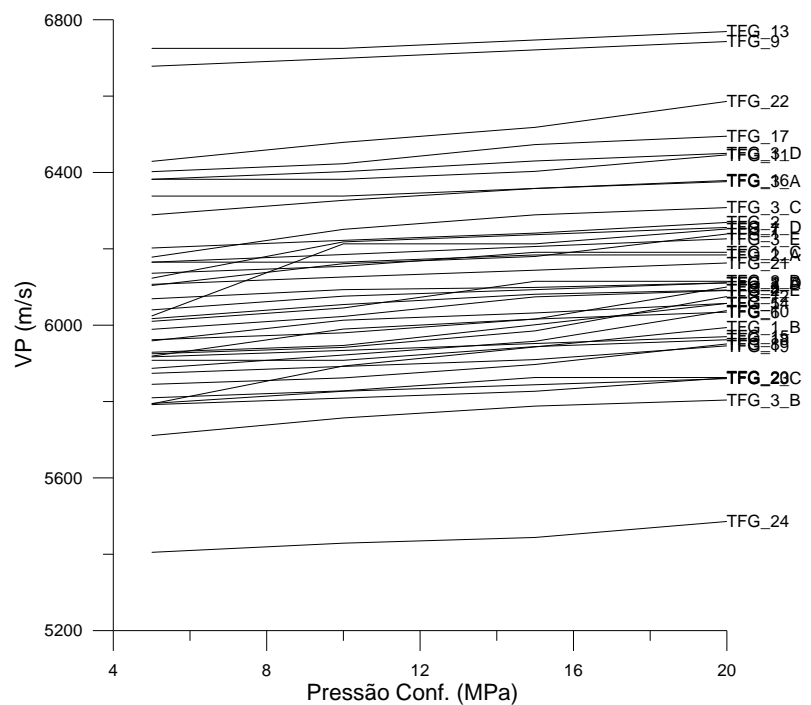

Figura 6 - Variação da velocidade da onda $P$ com a pressão confinante.

As Figuras 7 e 8 apresentam, respectivamente, as velocidades das ondas $S_{1}$ e $S_{2}$ em função da pressão confinante. Estas são ondas cisalhantes polarizadas no plano radial da amostra em direções mutuamente perpendiculares. A direção de polarização é aquela na qual as partículas se deslocam quando da passagem da onda. As velocidades das ondas $S_{1}$ e $S_{2}$ variam, no intervalo de pressões analisados, em cerca de $1000 \mathrm{~m} / \mathrm{s}$, apresentando aumento da velocidade com o aumento da pressão confinante. Disto resulta que, para uma dada pressão confinante, ocorre uma variação na velocidade das ondas $S_{1}$ e $S_{2}$, entre todas as amostras, respectivamente, de $30 \%$ e $29 \%$ em relação à velocidade média, o que corresponde a uma variação maior que a variação apresentada pela onda $P$.



Figura 7 - Variação da velocidade da onda $S_{1}$ com a pressão confinante.

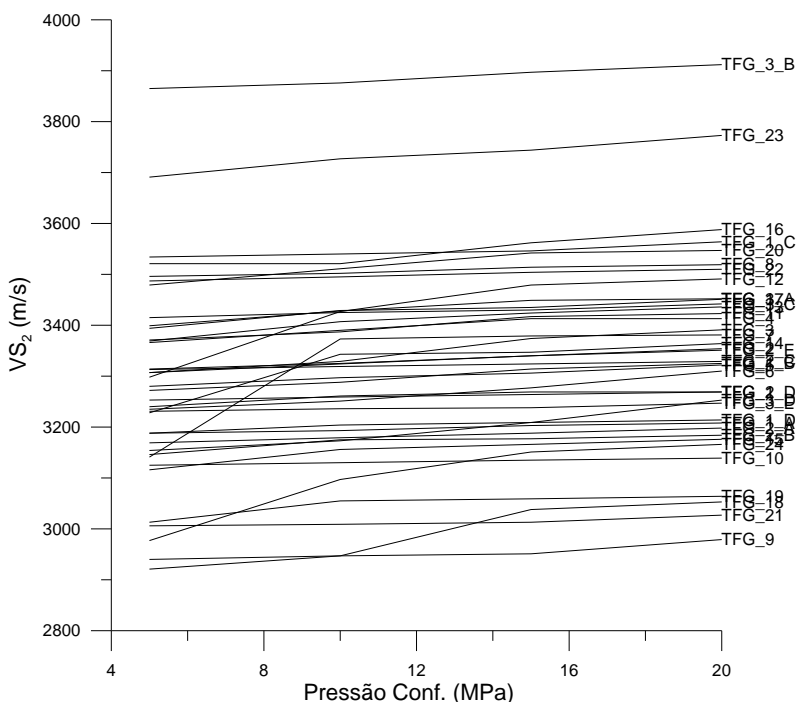

Figura 8 - Variação da velocidade da onda $S_{2}$ com a pressão confinante.

A Figura 9 apresenta a relação entre as velocidades das ondas $\mathrm{P}$ e $\mathrm{S}_{1}$ sob $20 \mathrm{MPa}$ de pressão confinante. Nesta figura se observa que há uma tendência de relação direta entre estas velocidades, embora com uma grande dispersão dos dados. Possivelmente esta dispersão 
acontece devido à variação composicional entre as amostras que, embora sejam do mesmo afloramento, podem conter teores variados, tanto na composição da matriz mineral quanto no conteúdo de matéria orgânica.

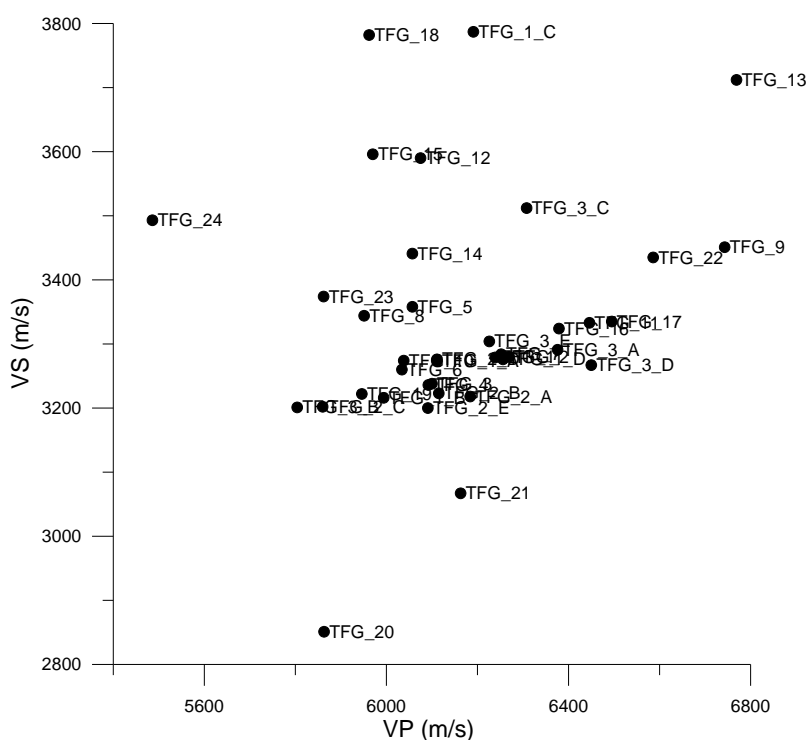

Figura 9 - Relação entre as velocidades das ondas $P$ e $S_{1}$ sob $20 \mathrm{MPa}$ de pressão confinante.

A Figura 10 apresenta a relação entre a razão das velocidades das ondas $S_{1}$ e $S_{2}$, sob $20 \mathrm{MPa}$ de pressão confinante, com a porosidade. Ela indica o grau de anisotropia elástica das amostras. Embora a maioria das amostras (31 amostras) apresente uma anisotropia relativamente baixa (inferior a 10\%), há 7 amostras cujo grau de anisotropia pode ser considerado médio (de 10\% a $25 \%$ ). O grau de anisotropia independe da porosidade.

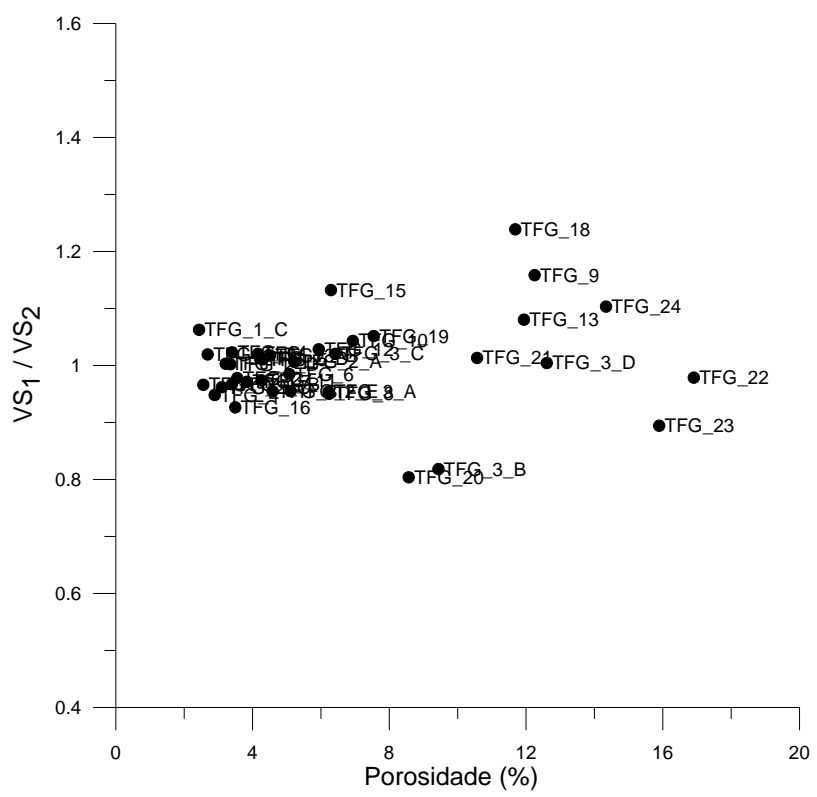

Figura 10 - Relação entre a razão das velocidades das ondas $\mathrm{S}_{1 \mathrm{e}} \mathrm{S}_{2}$ com a porosidade.
A Figura 11 apresenta os valores de densidade de grãos medidas nas amostras. Esta variável é um bom indicador da composição mineral das amostras. Considerando que as amostras são compostas essencialmente por uma matriz calcária, esperava-se uma densidade de grãos em torno de $2,71 \mathrm{~g} / \mathrm{cm}^{3}$. No entanto, quanto maior o teor de matéria orgânica, menor o valor da densidade de grãos. Portanto, os valores de densidade de grãos medidos indicam teores variados de matéria orgânica, o que é esperado em se tratando de tufas carbonáticas.



Figura 11 - Densidade de grãos medidas nas amostras.

A Figura 12 apresenta a relação da densidade total com a porosidade. A densidade total é dada pela razão entre a massa e o volume total da amostra. Ela é função tanto da densidade dos grãos minerais quanto do fluido contido nos poros. Como neste trabalho todas as amostras foram ensaiadas secas, a densidade total é influenciada apenas pela densidade de grãos e pelo valor da porosidade. Desta figura se observa que há uma relação linear entre a densidade total e a porosidade. A dispersão observada é causada pela variação composicional ou ainda pelos tipos de porosidade que ocorrem nas amostras.

A Figura 13 apresenta a relação entre a porosidade e a permeabilidade das amostras. Neste gráfico são também apresentadas as três regiões de Lucia (1995), as quais indicam 0 tamanho predominante de grãos. Considerando que toda a porosidade é do tipo não vugular, a região de menor permeabilidade, para um dado valor de porosidade, seria a região a ser ocupada por amostras com diâmetro de grão menor que $20 \mu \mathrm{m}$. Já a região que apresenta maior permeabilidade, para um dado valor de porosidade, seria a região a ser ocupada por amostras com grãos cujo diâmetro é maior que 100 $\mu \mathrm{m}$. Por fim, a região intermediária corresponderia àquelas amostras cujos grãos possuem diâmetro entre $20 \mu \mathrm{m}$ e $100 \mu \mathrm{m}$. Os valores medidos de permeabilidade e porosidade indicam, segundo o método de análise proposto por Lucia, uma grande variação granulométrica. No entanto, em caso da ocorrência de porosidade vugular ou microporosidade, amostras de granulometria elevada caem em regiões de menor granulometria. 


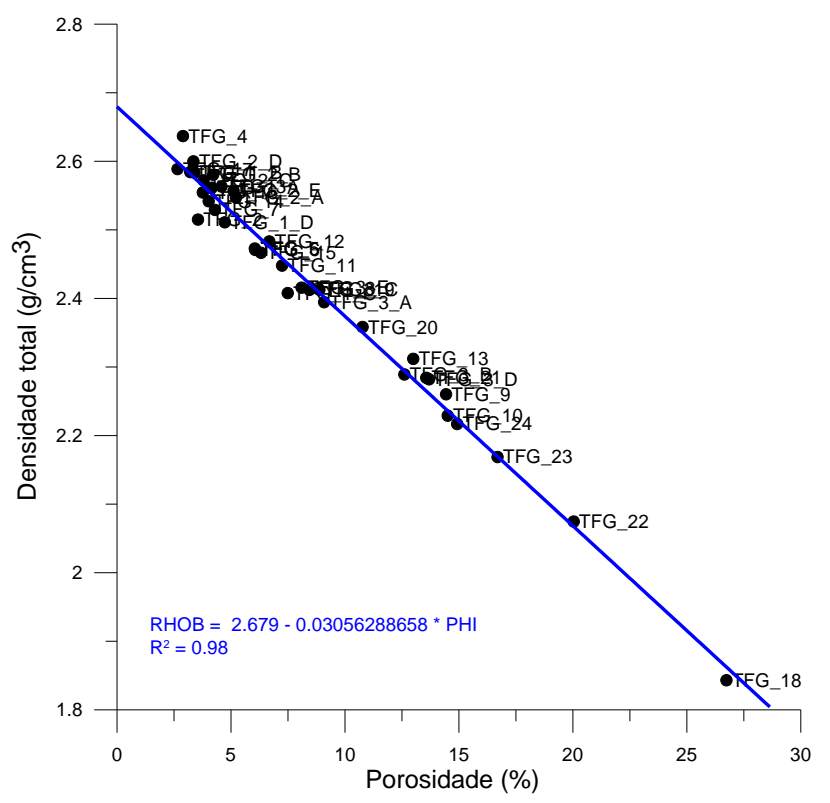

Figura 12 - Relação da densidade total com a porosidade.

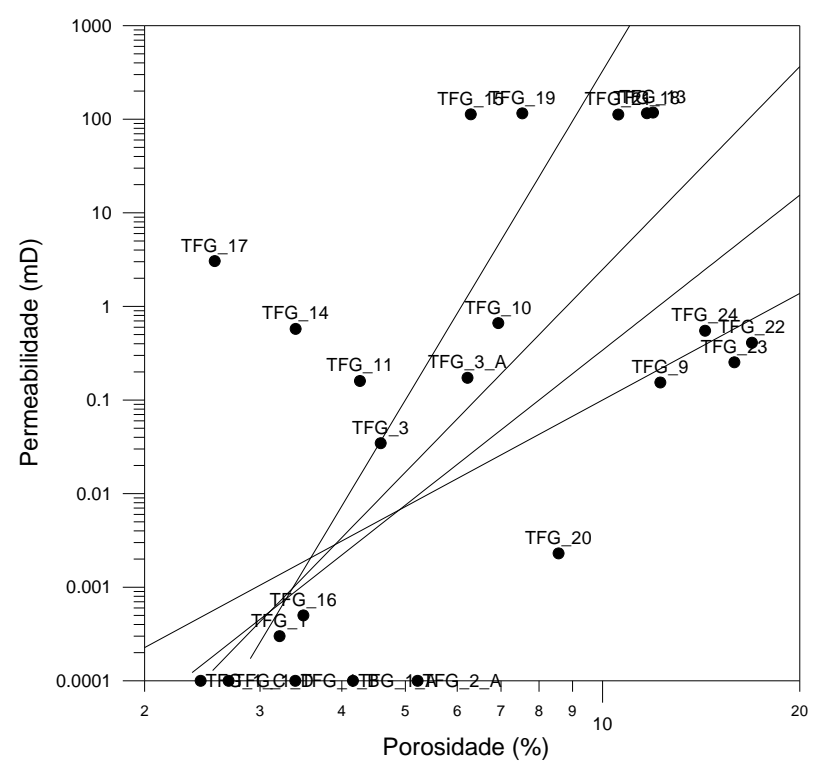

Figura 13 - Relação entre permeabilidade e porosidade.

As figuras 14 a 17 apresentam a relação entre os módulos elásticos e a porosidade, para pressão confinante de $20 \mathrm{MPa}$. A incompressibilidade, por representar a resistência da rocha à compactação, se comporta, em relação à porosidade, de modo semelhante à velocidade compressional. Já o módulo de cisalhamento, que representa a resistência da rocha à deformação cisalhante, e o módulo de elasticidade, que representa a resistência da rocha à deformação uniaxial, se comportam em relação à porosidade de modo semelhante à velocidade da onda $\mathrm{S}$.

Para estes três módulos elásticos se observa uma tendência geral de redução com 0 aumento da porosidade, embora com uma grande dispersão dos dados. Esta dispersão pode ser causada pela variação na composição e nos tipos de porosidade.



Figura 14 - Relação entre incompressibilidade e porosidade.

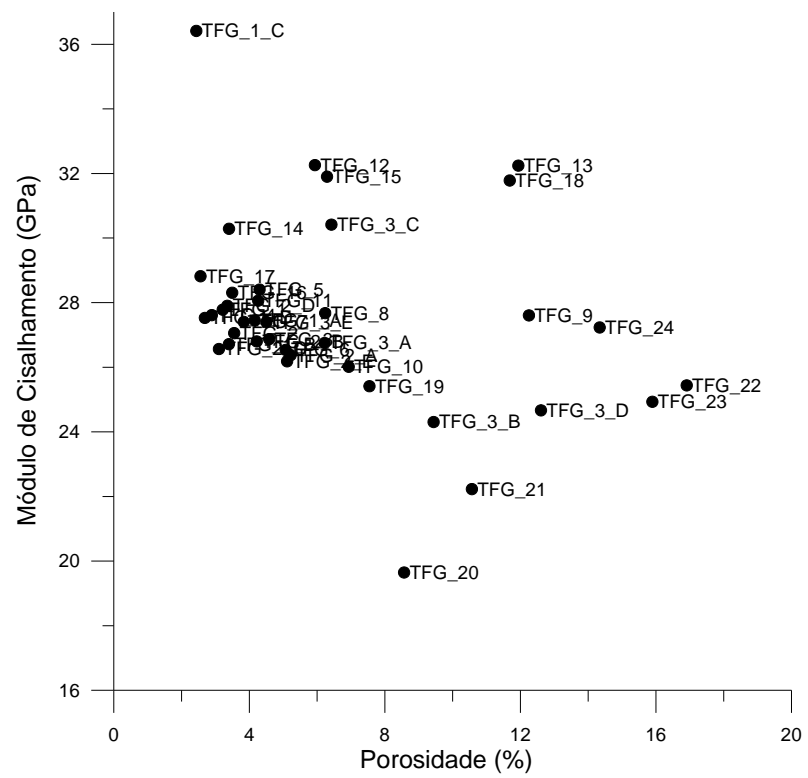

Figura 15 - Relação entre o módulo de cisalhamento e a porosidade.

A Figura 17 apresenta a relação entre a razão de Poisson e a porosidade, para pressão confinante de $20 \mathrm{MPa}$. Esta constante elástica depende do quadrado da razão entre VP e VS. A grande dispersão dos dados observada nesta figura sugere que, embora todas as amostras sejam de um mesmo afloramento, há uma variação composicional considerável entre elas. 


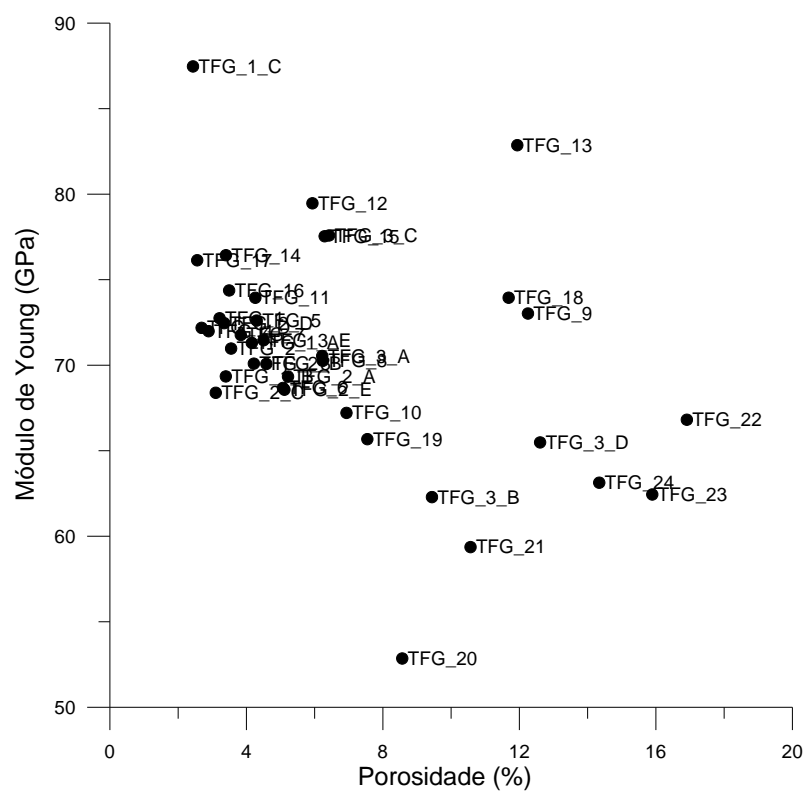

Figura 16 - Relação entre o módulo de elasticidade e a porosidade.

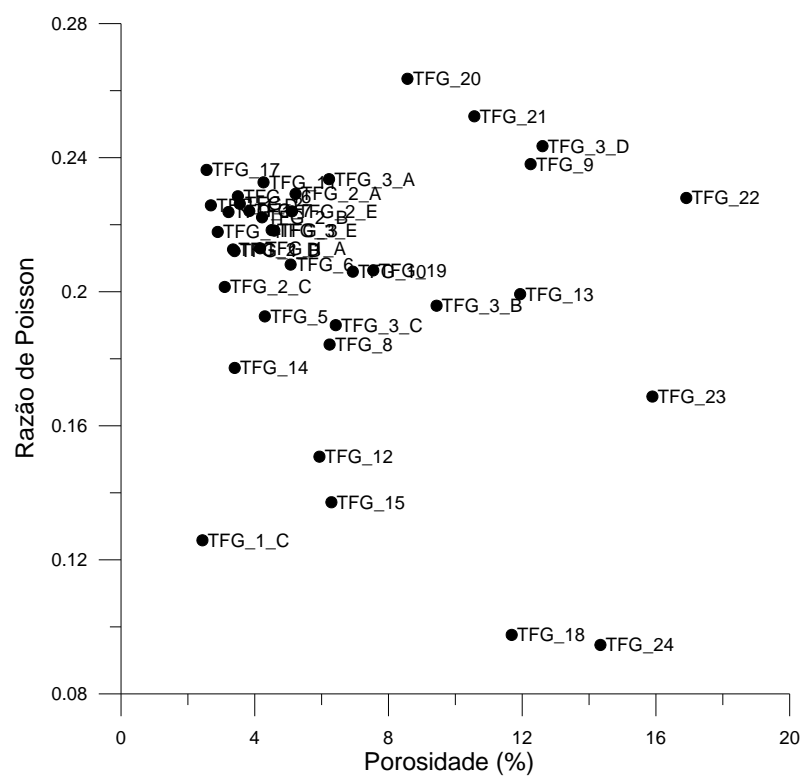

Figura 17 - Relação entre a razão de Poisson e a porosidade.

\section{Conclusões}

Considerando que a densidade de grãos é um bom indicador da composição mineral das amostras, os valores medidos para esta propriedade indicam teores variados de matéria orgânica. A relação entre as velocidades das ondas $P$ e $S$ também indica uma variação composicional entre as amostras.

Uma função de regressão linear entre a densidade total e a porosidade das amostras foi determinada. A dispersão dos dados em relação à regressão linear pode ser causada pela variação composicional ou ainda pela ocorrência de porosidade vugular não conectada e/ou microporosidade.

Os valores medidos de permeabilidade e porosidade indicam, segundo o método de análise proposto por Lucia para carbonatos com porosidade não-vugular, uma grande variação granulométrica. A ocorrência de porosidade dos tipos vugular e microporosidade faria com que as amostras caíssem na região de pequena granulometria. No entanto, diversas amostras caem na região de elevada granulometria, o que indica que de fato elas assim o são, e que apresentam pequena influência destes tipos especiais de porosidade.

No intervalo de pressões confinantes dos ensaios ocorre um aumento das velocidades elásticas com o aumento da pressão confinante. No caso da onda $P$ as velocidades das amostras variam cerca de $23 \%$ em relação à velocidade média. Já para o caso da onda $\mathrm{S}$, essa variação é de cerca $30 \%$.

A razão entre as velocidades das ondas $S_{1}$ e $S_{2}$ indica níveis variados de anisotropia, sendo que $82 \%$ das amostras apresentam uma anisotropia inferior a $10 \%$, enquanto que as demais apresentam grau de anisotropia entre $10 \%$ e $25 \%$.

Com relação aos módulos de elasticidade se observa uma tendência geral de redução destes com o aumento da porosidade, embora haja grande dispersão dos dados. Esta dispersão pode ser causada tanto pela variação composicional quanto pelos tipos de porosidade predominantes nas amostras.

\section{Referências}

CASSAB, R.C.T. (2003). Paleontologia da Formação Jandaíra, Cretáceo Superior da Bacia Potiguar com ênfase na Paleobiologia dos Gastrópodos. Tese de Doutorado. Programa de Pós-Graduação em Geologia, Universidade Federal do Rio de Janeiro.

CÓRDOBA, V.C. (2001). A evolução da plataforma carbonática Jandaíra durante o Neocretácio na Bacia Potiguar: Análise paleoambiental, diagenética e estratigráfica. Tese de Doutorado. Curso de Pós Graduação em Geociências, Universidade Estadual Paulista, Rio Claro, SP.

FORD, T.D; PEDLEY, H.M. (1996). A Review of Tufa and Travertine Deposits of the World. Earth-Science Reviews 41, p. 117-175.]

LUCIA, F.J. (1995). Rock fabric petrophysical classification of carbonate for reservoir characterization. AAPG Bulletin, V. 79, № 9, 1275-1300.

PÉREZ, Y.A.R. (2003). Caracterização da geometria de depósitos sedimentares na borda sudoeste da Bacia Potiguar. Dissertação de Mestrado. Programa de Pós Graduação em Geodinâmica e Geofísica, Universidade Federal do Rio Grande do Norte. Natal, RN.

SUGUIO, K. (2003). Geologia Sedimentar. Editora Blutcher. São Paulo, 400p. 